\title{
Goodpasture's Syndrome Associated with Primary Biliary Cirrhosis
}

\author{
Takeo Komatsu, Kazumasa Utsunomiya and Tatsuki OyaizU*
}

\begin{abstract}
A 73-year-old woman who had a history of primary biliary cirrhosis developed rapidly progressive glomerulonephritis and pulmonary-renal syndrome. She was found to have antimitochondrial antibody (AMA) and myeloperoxidase (MPO) anti-neutrophil cytoplasmic antibody (ANCA). She also had weak anti-glomerular basement membrane (GBM) antibody. She was treated with methylprednisolone pulse therapy, but died of respiratory failure. On postmortem examination, both lungs showed diffuse hemorrhage and the immunofluorescence study of the kidney revealed linear immunoglobulin G (IgG) deposition along the glomerular basement membrane.
\end{abstract}

(Internal Medicine 37: 611-613, 1998)

Key words: myeloperoxidase (MPO)- anti-neutrophil cytoplasmic antibody (ANCA), anti-mitochondrial antibody (AMA), anti-glomerular basement membrane (GBM) antibody, crescentic glomerulonephritis, pulmonary-renal syndrome

\section{Introduction}

Although Goodpasture's syndrome is rare in Japan, many cases of pulmonary-renal syndrome have been reported. Such pulmonary-renal syndromes are thought to be anti-neutrophil cytoplasmic antibody (ANCA)-related. Myeloperoxidase (MPO)-ANCA often coexists with other autoantibodies, including anti-glomerular basement membrane (GBM) antibody $(1,2)$. Primary biliary cirrhosis $(\mathrm{PBC})$, on the other hand, is an autoimmune disease rarely found to have ANCA. In this report, we describe a case of Goodpasture's syndrome associated with MPO-ANCA and anti-GBM antibody that developed in a 73year-old woman who has a history of PBC.

\section{Case Report}

A 73-year-old woman was admitted to Shizuoka City Hospital on December 11, 1996, because of anuria and worsening renal function. In August 1996, she was in the same hospital because of compression fracture of vertebral bone. For many years she had been known to have chronic liver disease, but the disease proved to be $\mathrm{PBC}$ when she was found to have antimitochondrial antibody (AMA) and an increased level of alkaline phosphatase. Her renal function was normal. As her PBC was asymptomatic, she was prescribed ursodesoxycholic acid and sent for rehabilitation to another hospital. On November 17, she was found to have macrohematuria and proteinuria without preceding episode of infection or exposure to chemicals. A few days later, her face and extremities became edematous. On December 7, her urine volume decreased, and laboratory studies disclosed abnormal renal function. On December 11, the temperature increased to $38.4^{\circ} \mathrm{C}$ and she came back to our hospital.

On physical examination she looked pale and dyspneic. Her temperature was $37.9^{\circ} \mathrm{C}$, blood pressure was $144 / 44 \mathrm{mmHg}$, and pulse was 90 . The respirations were 30 . Coarse rhonchi and crackles were heard over her entire chest wall and largely obscured the heart sounds. The abdomen was soft and her lower extremities were edematous. No rash or lesions indicative of vasculitis were seen. A specimen of arterial blood, drawn while she was breathing room air, disclosed partial pressure of oxygen $\left(\mathrm{PaO}_{2}\right) 53.4 \mathrm{mmHg}$, partial pressure of carbon dioxide $\left(\mathrm{PaCO}_{2}\right)$ $34.7 \mathrm{mmHg}$, and the $\mathrm{pH} 7.415$. Radiographs of the chest revealed diffuse opacification of both lungs and there was a small amount of pleural effusion. Electrocardiogram showed sinus tachycardia. Abdominal echography showed that bilateral kidneys were normal and hydronephrosis was not present. Laboratory studies are shown in Table 1.

She was thought to have acute renal failure with heart failure, and an emergent hemodialysis was begun. But even after hemodialysis radiographic findings of the chest were not improved, and $\mathrm{PaO}_{2}$ was $58.9 \mathrm{mmHg}$ while she was breathing $2 l l$

From the Division of Nephrology and *the Division of Gastroenterology, Shizuoka City Hospital, Shizuoka

Received for publication January 20, 1998; Accepted for publication April 21, 1998

Reprint requests should be addressed to Dr. Takeo Komatsu, the Division of Nephrology, Shizuoka City Hospital, 10-93, Ohtemachi, Shizuoka 420-8630 
Komatsu et al

Table 1. Laboratory Data on Admission

\begin{tabular}{|c|c|c|c|}
\hline \multicolumn{2}{|l|}{ Peripheral blood } & \multicolumn{2}{|l|}{ Urinalysis } \\
\hline White blood cell & $8,900 / \mu \mathrm{l}$ & $\mathrm{pH}$ & 6.0 \\
\hline Red blood cell & $308 \times 10^{4} / \mu 1$ & Protein & $(2+)$ \\
\hline Hemoglobin & $8.1 \mathrm{~g} / \mathrm{dl}$ & Occult blood & $(3+)$ \\
\hline Hematocrit & $24.9 \%$ & Sugar & $( \pm)$ \\
\hline \multirow[t]{2}{*}{ Platelet } & $40.3 \times 10^{4} / \mu 1$ & Urobilinogen & $( \pm)$ \\
\hline & & $\mathrm{RBC}$ & $>100 / \mathrm{HPF}$ \\
\hline Coagulation & & WBC & 10 19/HPF \\
\hline Prothrombin time & $9.7 \mathrm{~s}$ & Granular cast & $(+)$ \\
\hline Activated partial & & Creatinine clearance & $1.0 \mathrm{ml} / \mathrm{min}$ \\
\hline thromboplastin time & $31.1 \mathrm{~s}$ & Urine protein & $1.16 \mathrm{~g} /$ day \\
\hline Fibrinogen & $186.6 \mathrm{mg} / \mathrm{dl}$ & & \\
\hline \multirow{3}{*}{$\begin{array}{l}\text { Fibrin degradation } \\
\text { product }\end{array}$} & & Blood chemistry & \\
\hline & $17.4 \mu \mathrm{g} / \mathrm{ml}$ & Total protein & $5.8 \mathrm{~g} / \mathrm{dl}$ \\
\hline & & Albumin & $2.2 \mathrm{~g} / \mathrm{dl}$ \\
\hline \multicolumn{2}{|l|}{ Serology } & Blood urea nitrogen & $77 \mathrm{mg} / \mathrm{dl}$ \\
\hline Immunoglobulin G & $1,699 \mathrm{mg} / \mathrm{dl}$ & Creatinine & $7.5 \mathrm{mg} / \mathrm{dl}$ \\
\hline Immunoglobulin A & $374 \mathrm{mg} / \mathrm{dl}$ & Uric acid & $5.4 \mathrm{mg} / \mathrm{dl}$ \\
\hline Immunoglobulin $\mathrm{M}$ & $344 \mathrm{mg} / \mathrm{dl}$ & Glucose & $102 \mathrm{mg} / \mathrm{dl}$ \\
\hline $\mathrm{C} 3$ & $79 \mathrm{mg} / \mathrm{dl}$ & Total bilirubin & $0.3 \mathrm{mg} / \mathrm{dl}$ \\
\hline $\mathrm{C} 4$ & $29 \mathrm{mg} / \mathrm{dl}$ & Aspartate aminotransferase & $20 \mathrm{U} / \mathrm{l}$ \\
\hline \multirow[t]{2}{*}{$\mathrm{CH} 50$} & $35.9 \mathrm{U} / \mathrm{ml}$ & Alanine aminotransferase & $8 \mathrm{U} / l$ \\
\hline & & Alkaline phosphatase & $300 \mathrm{U} / l$ \\
\hline \multicolumn{2}{|l|}{ Immunology } & Lactate dehydrogenase & $609 \mathrm{U} / l$ \\
\hline Anti-nuclear antibody & $(-)$ & Creatine phosphokinase & $45 \mathrm{U} / l$ \\
\hline Rheumatoid factor & $56 \mathrm{U} / \mathrm{ml}$ & Total cholesterol & $251 \mathrm{mg} / \mathrm{dl}$ \\
\hline Cryoglobulin & $(-)$ & $\mathrm{Na}$ & $134 \mathrm{mEq} / \mathrm{l}$ \\
\hline MPO-ANCA & $394 \mathrm{EU}$ & $\mathrm{K}$ & $4.4 \mathrm{mEq} / \mathrm{l}$ \\
\hline C-ANCA & $<10 \mathrm{EU}$ & $\mathrm{Cl}$ & $106 \mathrm{mEq} / \mathrm{l}$ \\
\hline Anti-GBM antibody & $14 \mathrm{EU}$ & $\mathrm{Ca}$ & $7.8 \mathrm{mg} / \mathrm{dl}$ \\
\hline \multirow[t]{2}{*}{ AMA } & $\times 256$ & $\mathrm{Pi}$ & $5.4 \mathrm{mg} / \mathrm{dl}$ \\
\hline & & $\mathrm{C}$ reactive protein & $7.1 \mathrm{mg} / \mathrm{dl}$ \\
\hline
\end{tabular}

MPO-ANCA: myeloperoxidase anti-neutrophil cytoplasmic antibody, Anti-GBM antibody: anti-glomerular basement membrane antibody, AMA: anti-mitochondrial antibody.

min oxygen. We considered the possibility of rapidly progressive glomerulonephritis with pulmonary-renal syndrome, so she had methylprednisolone pulse therapy $(500 \mathrm{mg} /$ day, for 3 days). On December 16, cyanosis developed and an endotracheal tube was inserted. Blood-tinged sputa often spouted. On December 18 , we knew that MPO-ANCA was positive $(\times 394)$ and anti-GBM antibody was slightly elevated $(\times 14)$, but her general status was so bad that we could not attempt plasmapheresis therapy. She died of respiratory failure on December 20.

An autopsy was performed. The renal findings included crescentic glomerulonephritis, with over $90 \%$ of the glomeruli showing crescents (Fig. 1). Most of the crescents were fibrocellular, and there was diffuse tubular atrophy. Immunofluorescence study revealed linear staining of the GBM for immunoglobulin G (IgG) (Fig. 2). Crescents were also stained for fibrin related antigen. Histologic examination of the lung revealed blood-filled alveoli and hemosiderin-laden macrophages. Immunological study showed staining of the alveolar basement membrane for IgG. The liver specimen was

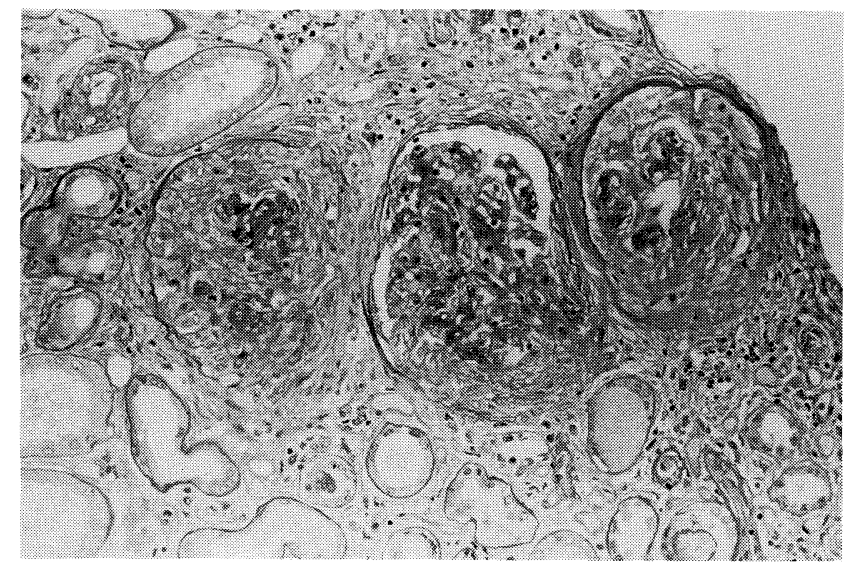

Figure 1. Light microscopic examination revealed crescentic glomerulonephritis with over $90 \%$ of the glomeruli showing crescent formation (PAS stain, $\times \mathbf{2 0 0})$. 


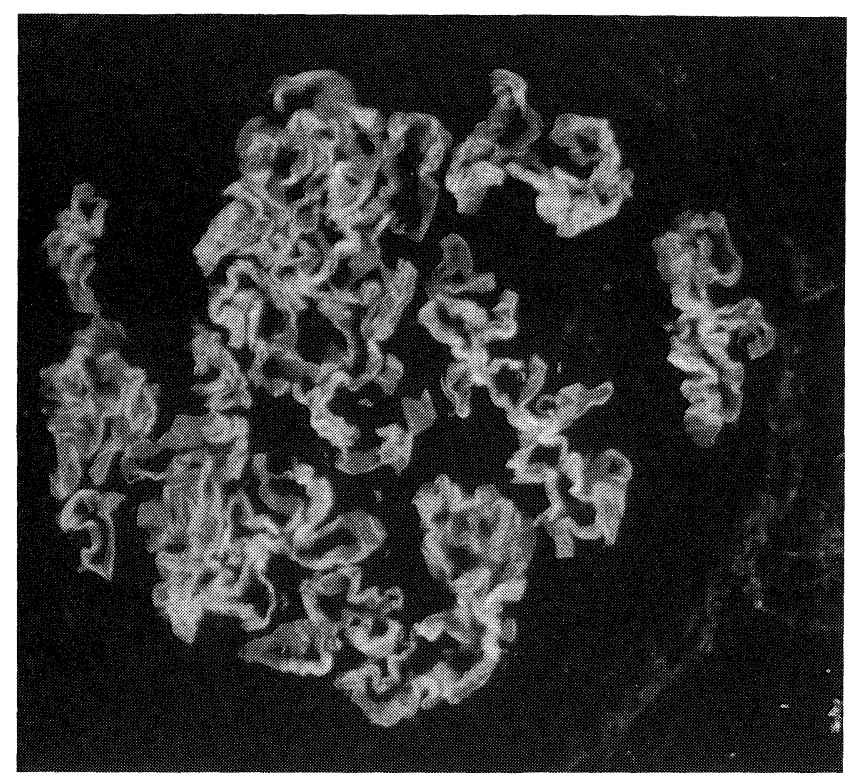

Figure 2. Immunofluorescence study revealed linear staining of the glomerular basement membrane for IgG $(\times 400)$.

sent to Kansai Medical University for the evaluation of PBC. According to the report, the liver change was consistent with PBC (stage II). There were no changes indicative of systemic vasculitis in other organs, such as skin, nerves, and gastrointestinal tract.

\section{Discussion}

The main feature of this case report is pulmonary-renal syndrome which can be attributed either to anti-GBM antibody or to MPO-ANCA. The titer of anti-GBM antibody was low but the histological appearance of linear IgG deposition strongly suggested that crescentic glomerulonephritis and pulmonary hemorrhage were related to anti-GBM antibody. Since the coexistence of anti-GBM antibodies and ANCA is widely recognized $(1,2)$, it does not seem to be meaningful to discuss which of the two antibodies played a dominant role in this case (3). Autopsy revealed pulmonary hemorrhage and no systemic vasculitis, so we thought this case was Goodpasture's syndrome.

Although the clinical course was very rapidly progressive, we could attempt plasmapheresis therapy when we considered the possibility of pulmonary-renal syndrome. However, it was too late when we learned that the tests for MPO-ANCA and anti-GBM antibody were positive. It may be helpful to attempt plasmapheresis therapy together with steroid pulse therapy when a patient shows rapidly progressive glomerulonephritis with pulmonary-renal syndrome.

What is unique to our patient is that she had a long history of chronic liver disease and that AMA was positive. Patients with PBC often have other auto-immune diseases, such as Sjögren's syndrome, chronic thyroiditis, and rheumatoid arthritis (4), but the association of PBC with pulmonary-renal syndrome has not been recognized. MPO-ANCA was described in sera from a patient with PBC (5), but the reported patient did not develop ANCA-related vasculitis. Therefore, the pathogenetic importance of ANCA in the development of PBC is not established (6, $7)$. In this case, there is clinical and histological evidence that she actually developed both pulmonary-renal syndrome and PBC. Since the onset of pulmonary-renal syndrome does not seem to be close to the onset of PBC, it may not be convincing to say that $\mathrm{PBC}$ could be complicated with pulmonary-renal syndrome or ANCA-related vasculitis. An autoimmune mechanism is assumed in the development of those diseases, however, it is likely that immunological disturbance which activated AMA may influence the subsequent development of pulmonary-renal syndrome.

Acknowledgements: The authors gratefully appreciate Prof. Kyoichi Inoue of Kansai Medical University for his kind evaluation and comments on our liver specimen.

\section{References}

1) Jayne DRW, Marshall PD, Jones SJ, Lockwood CM. Autoantibodies to GBM and neutrophil cytoplasm in rapidly progressive glomerulonephritis. Kidney Int 37: 965, 1990.

2) Bosch X, Mirapeix E, Font J, et al. Prognostic implication of antineutrophil cytoplasmic autoantibodies with myeloperoxidase specificity in anti-glomerular basement membrane disease. Clin Nephrol 36: 107, 1991.

3) Case Records of the Massachusetts General Hospital. Weekly clinicopathological exercises. Case 52-1993. N Engl J Med 329: 2019, 1993.

4) Kaplan MM. Primary biliary cirrhosis. N Engl J Med 335: 1570, 1996.

5) Cohen Tervaert JW, Mulder AHL, Horst G, Haagsma EB, Kleibeuker JH, Kallenberg CGM. Antineutrophil cytoplasmic antibodies in primary sclerosing cholangitis, ulcerative colitis, and autoimmune diseases. Gastroenterology 102: 1090, 1992 (letter).

6) Orth T, Gerken G, Meyer zum Buschenfelde KH, Mayet WJ. Antineutrophil nuclear antibodies (ANNA) in primary biliary cirrhosis: Their prevalence and antigen specificity. Z Gastroenterol 35: 113, 1997.

7) Kallenberg CGM, Mulder AHL, Cohen Tervaert JW. Antineutrophil cytoplasmic antibodies: a still-growing class of autoantibodies in inflammatory disorders. Am J Med 93: 675, 1992. 